Received: 10 July 2018

Accepted: 25 January 2019

Published online: 25 February 2019

\section{Associations of maternal, perinatal and postnatal factors with the eruption timing of the first primary tooth}

\author{
Huaying Wu$u^{1,2}$, Ting $\mathrm{Chen}^{3}$, Qian $\mathrm{Ma}^{1}$, Xiangqin $\mathrm{Xu}^{1,2}$, Kaipeng $\mathrm{Xie}^{3,4,5}$ \& Yaming Chen ${ }^{1}$
}

We recruited 1296 mothers in their first trimester from the Affiliated Obstetrics and Gynecology Hospital of Nanjing Medical University between May 2014 and September 2015 to investigate the associations of maternal, perinatal and postnatal factors with the eruption timing of the first primary tooth (ETFPT) in a Chinese population. We collected maternal demographic information and clinical data during the perinatal and postnatal period, and oral examinations of the infants were performed by a doctor at 6, 9 and 12 months of age. Multiple regression analysis was used to identify significant explanatory variables for ETFPT. The mean age at eruption of the first primary tooth for all the infants was $6.82 \pm 1.90$ months. After adjustment for confounders, higher maternal childbearing age $(\beta=0.57 ; 95 \% \mathrm{Cl}=0.13-1.02)$, female sex $(\beta=0.26 ; 95 \% \mathrm{Cl}=0.07-0.52)$, and low birth weight $(\beta=0.98$; $95 \% \mathrm{Cl}=0.20-1.76$ ) were significantly associated with delayed eruption of the first primary tooth, while macrosomia $(\beta=-0.79 ; 95 \% \mathrm{Cl}=-1.30--0.28)$ was significantly associated with earlier eruption of the first primary tooth. Maternal childbearing age, infant sex and infant birth weight were significant determinants of ETFPT.

The formation and development of human primary teeth begins at the end of the fifth week of gestation ${ }^{1}$. Teeth are formed in the upper and lower jaw through mutual, subtle and sophisticated interactions between the dental epithelium and oral ectomesenchyme involving the expression of several tooth-related genes ${ }^{1}$. Primary tooth eruption is a complex and highly regulated process in which teeth enter the mouth and become visible during a certain time period. In most infants, the first primary tooth to erupt is the central mandibular incisor, which erupts between 2 and 15 months of age ${ }^{2}$. The complete primary dentition erupts from 10 to 33 months depending on the position and type of tooth ${ }^{3}$.

Variations in the eruption timing of the first primary tooth (ETFPT) are considered multifactorial. Eruption is under strong genetic control, and the estimates of narrow-sense heritability are over $70 \%{ }^{4}$. Furthermore, genome-wide association studies (GWAS) have identified some candidate genes associated with tooth development, such as KCNJ2, EDA, HOXB2, RAD51L1, IGF2BP1, HMGA2 and MSRB3 ${ }^{5}$. There are ethnicity- and sex-related differences in the timing of primary tooth eruption ${ }^{6}$. However, external environmental factors also make significant contributions to the timing of the primary tooth eruption. Maternal exposure to tobacco during pregnancy ${ }^{7,8}$, infant birth weight ${ }^{9,10}$, birth length ${ }^{11}$, nutritional state at birth and at postnatal timepoints ${ }^{12}$, gestational age ${ }^{13}$, method of infant feeding ${ }^{8,14}$ and socioeconomic situation ${ }^{15}$ have been reported to be significant determinants of the eruption of primary teeth. Delayed tooth eruption has been reported in premature infants $s^{13,16}$

${ }^{1}$ Department of Polyclinics, The Affiliated Stomatological Hospital of Nanjing Medical University, Nanjing, 210029, China. ${ }^{2}$ Department of Stomatology, The Affiliated Obstetrics and Gynecology Hospital of Nanjing Medical University, Nanjing Maternity and Child Health Care Hospital, Nanjing, 210004, China. ${ }^{3}$ Nanjing Maternity and Child Health Care Institute, The Affiliated Obstetrics and Gynecology Hospital of Nanjing Medical University, Nanjing Maternity and Child Health Care Hospital, Nanjing, 210004, China. ${ }^{4}$ Department of Women Health Care, The Affiliated Obstetrics and Gynecology Hospital of Nanjing Medical University, Nanjing Maternity and Child Health Care Hospital, Nanjing, 210004, China. ${ }^{5}$ State key Laboratory of Reproductive Medicine, The Affiliated Obstetrics and Gynecology Hospital of Nanjing Medical University, Nanjing Maternity and Child Health Care Hospital, Nanjing, 210004, China. Correspondence and requests for materials should be addressed to K.X. (email: kaipengxie@njmu. edu.cn) orY.C. (email: yaming_chen@njmu.edu.cn) 
with small gestational age and low birth weight and in those with systemic disorders, such as hypothyroidism ${ }^{17}$, while accelerated tooth eruption has been observed in children whose mothers smoked during pregnancy $\mathrm{y}^{7,8}$ as well as in those with childhood obesity ${ }^{18}$ and diabetes mellitus ${ }^{19}$.

Although several studies have examined the factors influencing tooth eruption, their results are inconsistent ${ }^{8,14,20-22}$. Most of the studies focused only on factors within a defined period of time and based their findings on evidence from small cohorts, while some studies focused on the whole pregnancy. A prospective cohort study in Turkey ${ }^{23}$ found that growth parameters and feeding patterns may be determinants of the timing of tooth eruption. The GUSTO cohort study in Singapore ${ }^{24}$ found that infant weight gain from birth to 3 months, ethnicity and maternal childbearing age were associated with the timing of the eruption of the first tooth. A study from the Southampton Women's Survey ${ }^{25}$ found that maternal smoking and socioeconomic status were associated with tooth eruption. Taken together, these cohort studies ${ }^{23-25}$ were based on relatively large populations and focused on comprehensive data, including maternal, perinatal and postnatal data; in contrast, their results are not entirely consistent.

There is definite evidence that children in different geographic regions have different eruption timing of the primary teeth ${ }^{26,27}$. Importantly, other factors, including socioeconomic factors, nutritional status, maternal educational levels and overall maternal health vary from country to country ${ }^{14,28}$. In the United States, primary tooth eruption timing differs among American Indian, Black and White children ${ }^{29}$. The GUSTO cohort study in Singapore ${ }^{24}$ found that compared to Chinese children, Malay and Indian children experienced significantly delayed tooth eruption. Meanwhile, primary tooth eruption timing differs between Indian children in Singapore ${ }^{24}$ and in India ${ }^{30,31}$. However, there is a lack of population data for residents in Nanjing of China. Therefore, our study aimed to evaluate the relationships between maternal, perinatal and postnatal factors and ETFPT of infants in a large cohort of Chinese mothers in Nanjing, China.

\section{Results}

Subject characteristics. The demographic and clinical characteristics of 1109 mother-child pairs are shown in Table 1 . The maternal childbearing age ranged from 20 to 41 years. Among the mothers, 84 (7.57\%) were over 35 years of age, and $50(4.51 \%)$ gave birth at a gestational age of less than 37 weeks. Among the infants, 524 $(47.20 \%)$ were females, $26(2.34 \%)$ were classified as low birth weight $(<2500 \mathrm{~g})$ and $58(5.23 \%)$ had macrosomia (>4000g).

ETFPT. The mean ETFPT of all the infants was $6.82 \pm 1.90$ months. As shown in Table 1, ETFPT was significantly delayed in infants born to mothers older than 35 years, infants with a low gestational age and infants with low birth weight, while the ETFPT was earlier in male infants and those with macrosomia (all $p<0.05$ ). Interestingly, the first eruption peak for both females and males was 6 months, and the second peak was 8 months (Fig. 1). Within the first 7 months of life, $68.55 \%$ of the males had erupted their first primary tooth, compared with only $60.88 \%$ of the females $(p=0.008$ ) (Fig. 2 ).

Potential determinants of ETFPT. Several factors showed significant associations with ETFPT in the univariate analysis, including maternal factors, such as increased maternal childbearing age and low gestational age, and perinatal and postnatal factors, such as female sex, low birth weight and macrosomia (all $p<0.05$, Table 2). No significant associations with ETFPT were observed for other maternal, perinatal and postnatal factors, including exposure to secondhand smoke during pregnancy, prepregnancy body mass index (BMI), feeding model or breast feeding duration. The multivariate analysis indicated that the significant determinants of ETFPT were maternal childbearing age and infant sex and birth weight. Mothers of higher maternal childbearing age $(\beta=0.57$, $95 \% \mathrm{CI}=0.13-1.02, p=0.010)$, female infants $(\beta=0.26,95 \% \mathrm{CI}=0.07-0.52, p=0.022)$, and low infant birth weight $(\beta=0.98,95 \% \mathrm{CI}=0.20-1.76, p=0.010)$ were significantly associated with delayed ETFPT, while macrosomia $(\beta=-0.79,95 \% \mathrm{CI}=-1.30--0.28, p=0.000)$ was significantly associated with earlier ETFPT (Table 2$)$.

\section{Discussion}

In this prospective study, we systematically analyzed the association of maternal, perinatal and postnatal factors with the ETFPT. We observed that the first eruption peak for all infants was in the 6th month, and the second peak was in the 8th month. However, the ETFPT was earlier in male infants than in females. Subsequently, we found that higher maternal childbearing age and low birth weight were significantly associated with delayed ETFPT, while macrosomia was significantly associated with earlier ETFPT.

Comparing our study with the GUSTO study ${ }^{24}$ revealed some differences in results. First, we found substantial differences $(p<0.001)$ in the ETFPT between Chinese children in Nanjing, China, and Singapore. The mean ETFPT of all the infants in our study was $6.82 \pm 1.90$ months, while in the GUSTO study in Singapore, the mean ETFPT of the Chinese children was $7.80 \pm 2.20$ months. Similarly, the mean ETFPT of Indian children was $8.15 \pm 1.69$ months in a major city in North India ${ }^{30}$ and $9.50 \pm 2.70$ months in Singapore ${ }^{24}$. Meanwhile, another study in India reported that the mean ETFPT of Indian children in Bhopal was $11.40 \pm 3.43$ months $^{31}$. Although differences in tooth eruption timing between shared ancestry populations in different countries/communities do exist, the reasons may include nutrition, socioeconomic status, climate, and environmental factors, such as the fluoride content in drinking water ${ }^{30}$. Common environmental toxins can also affect tooth development in human embryos $^{32}$. However, for any one factor, the results are inconsistent and inconclusive. The tooth eruption timing reported in this study differs from those reported in longitudinal studies in other countries ${ }^{33,34}$, suggesting that population-level differences in the ETFPT may exist. The ETFPT is ethnicity and community dependent. Since the current standards of primary teeth eruption timing are based mainly on Western populations, our data can be used as a reference for future clinical studies in Nanjing of China. 


\begin{tabular}{|c|c|c|c|c|c|c|c|}
\hline \multirow[b]{2}{*}{ Factors } & \multirow[b]{2}{*}{$\mathrm{N}(\%)$} & \multicolumn{4}{|c|}{ ETFPT (months) } & \multirow[b]{2}{*}{$p^{a}$} & \multirow[b]{2}{*}{$P^{b}$} \\
\hline & & Mean & SD & Minimum & Maximum & & \\
\hline & Total $=1109$ & 6.82 & 1.90 & 3.0 & 13.0 & & \\
\hline \multicolumn{8}{|c|}{ Mother's childbearing age (years) } \\
\hline$<25$ & $41(3.70 \%)$ & 6.90 & 2.51 & 4.0 & 12.0 & 0.755 & 0.452 \\
\hline $25-35$ & $984(88.73 \%)$ & 6.78 & 1.87 & 3.0 & 13.0 & - & - \\
\hline$>35$ & $84(7.57 \%)$ & 7.31 & 1.92 & 4.0 & 13.0 & 0.014 & 0.014 \\
\hline \multicolumn{8}{|c|}{ Exposure to secondhand smoke } \\
\hline Yes & $150(13.53 \%)$ & 7.01 & 1.95 & 3.0 & 13.0 & 0.192 & 0.261 \\
\hline No & $959(86.47 \%)$ & 6.80 & 1.89 & 3.0 & 13.0 & - & - \\
\hline \multicolumn{8}{|c|}{ Prepregnancy BMI $\left(\mathrm{kg} / \mathrm{m}^{2}\right)$} \\
\hline$<18.5$ & $102(9.20 \%)$ & 6.86 & 1.98 & 3.0 & 13.0 & 0.846 & 0.924 \\
\hline $18.5-23.9$ & $929(83.77 \%)$ & 6.82 & 1.89 & 3.0 & 13.0 & - & - \\
\hline $24.0-27.9$ & $66(5.95 \%)$ & 6.76 & 1.98 & 4.0 & 11.0 & 0.809 & 0.620 \\
\hline$\geq 28.0$ & $12(1.08 \%)$ & 7.21 & 1.97 & 4.0 & 10.0 & 0.480 & 0.364 \\
\hline \multicolumn{8}{|l|}{ Parity } \\
\hline Multiparous & $183(16.50 \%)$ & 6.71 & 1.71 & 3.0 & 11.0 & 0.342 & 0.607 \\
\hline Primiparous & $926(83.50 \%)$ & 6.85 & 1.94 & 3.0 & 13.0 & - & - \\
\hline \multicolumn{8}{|c|}{ Gestational age (weeks) } \\
\hline$<37$ & $50(4.51 \%)$ & 7.39 & 1.78 & 4.0 & 13.0 & 0.032 & 0.021 \\
\hline$\geq 37$ & $1059(95.49 \%)$ & 6.80 & 1.90 & 3.0 & 13.0 & - & - \\
\hline \multicolumn{8}{|l|}{ Mode of delivery } \\
\hline Caesarean & $431(38.86 \%)$ & 6.82 & 1.94 & 3.0 & 13.0 & 0.919 & 0.668 \\
\hline Vaginal & $678(61.14 \%)$ & 6.83 & 1.88 & 3.0 & 13.0 & - & - \\
\hline \multicolumn{8}{|l|}{ Infant sex } \\
\hline Female & $524(47.20 \%)$ & 6.98 & 1.91 & 3.0 & 13.0 & 0.009 & 0.007 \\
\hline Male & $585(52.80 \%)$ & 6.68 & 1.89 & 3.0 & 13.0 & - & - \\
\hline \multicolumn{8}{|l|}{ Birth weight (g) } \\
\hline$<2500$ & $26(2.34 \%)$ & 8.23 & 1.68 & 5.5 & 11.0 & $<0.001$ & $<0.001$ \\
\hline $2500-4000$ & $1025(92.43 \%)$ & 6.84 & 1.89 & 3.0 & 13.0 & - & - \\
\hline$>4000$ & $58(5.23 \%)$ & 5.91 & 1.70 & 3.0 & 11.0 & $<0.001$ & $<0.001$ \\
\hline \multicolumn{8}{|l|}{ Feeding model } \\
\hline Breast feeding & $207(18.67 \%)$ & 6.97 & 1.92 & 3.0 & 13.0 & 0.236 & 0.154 \\
\hline Artificial feeding & $40(3.61 \%)$ & 6.68 & 1.76 & 3.0 & 10.5 & 0.699 & 0.801 \\
\hline Mixed feeding & $862(77.73 \%)$ & 6.80 & 1.90 & 3.0 & 13.0 & - & - \\
\hline \multicolumn{8}{|c|}{ Breast feeding duration (months) } \\
\hline$<6$ & $90(8.12 \%)$ & 6.98 & 2.10 & 3.0 & 13.0 & 0.423 & 0.633 \\
\hline$\geq 6$ & $1019(91.88 \%)$ & 6.81 & 1.88 & 3.0 & 13.0 & - & - \\
\hline
\end{tabular}

Table 1. Demographic characteristics, ETFPT, and the significance of their association in 1109 mother-child pairs. ${ }^{a} p$ values were determined by Student's t-tests compared to the reference group. ${ }^{b} p$ values were determined by Mann-Whitney U-test compared to the reference group. *Abbreviations: ETFPT is eruption timing of the first primary tooth, $\mathrm{N}$ is sample size, $\mathrm{SD}$ is standard deviation, $\mathrm{kg}$ is kilograms, $\mathrm{m}$ is meters, $\mathrm{g}$ is grams.

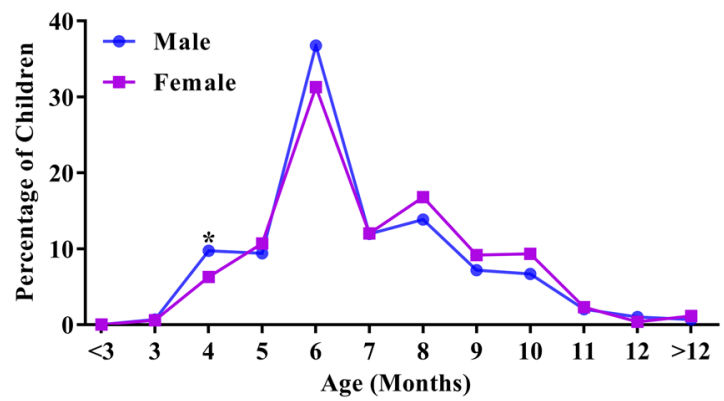

Figure 1. Distribution of 1109 children according to the eruption timing of the first primary tooth (males, females). $* P<0.05$. 


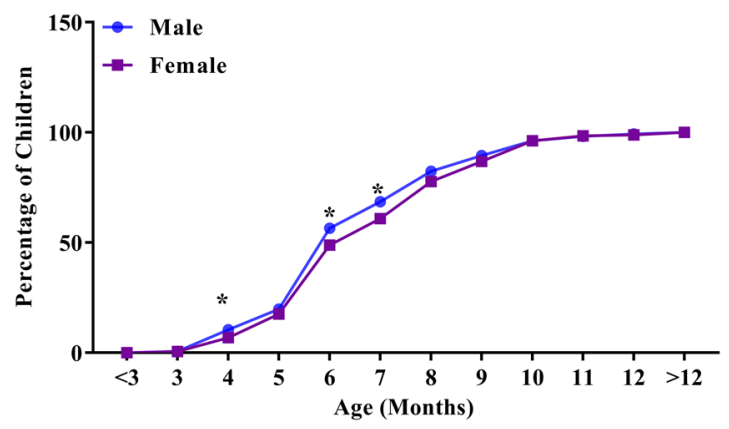

Figure 2. Cumulative distribution of 1109 children according to the eruption timing of the first primary tooth (males, females) $* P<0.05$.

Furthermore, our study showed that maternal childbearing age as a continuous variable have no statistics significance, however as a ordinal variable that increasing maternal childbearing age is associated with delayed ETFPT in infants. This finding disagrees with the results of the GUSTO study in Singapore ${ }^{24}$, which previously uncovered an association between higher maternal childbearing age and earlier ETFPT in infants. Previous work has demonstrated a similar relationship between maternal childbearing age and child growth parameters in which increased maternal childbearing age was associated with taller stature in children - on average, children of mothers who were older than 30 years at childbirth were $1.5 \mathrm{~cm}$ taller than those of mothers who were younger than 30 years $^{35}$. The mechanisms underlying these differences are unclear but may include ethnic or population history differences and environmental and/or genetic factors. Additionally, the literature suggests that factors such as ethnicity or population history may influence tooth formation and eruption ${ }^{36}$

The GUSTO study in Singapore ${ }^{24}$ did not find a sex-related difference; however, in the present study, we found a sex difference in the ETFPT, which was earlier in males. Our results align with previous studies that found that the primary teeth erupt earlier in males than in females ${ }^{37-40}$. The reason for the differences in the timing of tooth eruption between males and females is poorly understood. We hypothesize that the earlier onset of the primary dentition is related to differences in sexual maturity and may be partially attributed to environmental and/or genetic influences on growth ${ }^{41}$.

Previous studies have also suggested that the timing of primary tooth eruption is significantly related to general somatic growth and nutritional status ${ }^{42}$. Birth weight has been used as a marker of intrauterine nutritional environment, with low birth weight indicating poor fetal nutrition. Additionally, children who have experienced nutritional deficiencies show delayed primary teeth eruption ${ }^{43}$. Interestingly, we found that the first primary tooth eruption occurred earlier in infants with macrosomia, while it was delayed in infants with low birth weight; these findings are consistent with studies that focused on other populations ${ }^{44,45}$. Even when chronological age was adjusted for prematurity, infants with low birth weight have been shown to have greater likelihood of delayed ETFPT $^{46}$

According to previous research, there was an association between the earlier eruption of permanent teeth and childhood obesity ${ }^{18}$. Similarly, the GUSTO study in Singapore ${ }^{24}$ reported that earlier tooth eruption was associated with infant weight gain from birth to 3 months. Additionally, our study demonstrated that macrosomia is associated with earlier eruption of the primary teeth. Because birth weight is related to pregnancy and perinatal nutritional status and conditions, the findings of this study also suggest that primary tooth eruption may be an indicator of the nutritional status of the mother during pregnancy. As a result, we proposed that adequate nutrition during pregnancy and early life may prevent delayed ETFPT in infants.

Previous studies have also found that children born to mothers who smoked during pregnancy had an earlier ETFPT $^{7}$. Reports indicate that only $2.4 \%$ of the women in China are tobacco smokers ${ }^{47}$, and most women who do smoke quit after they became pregnant ${ }^{48}$. Few mothers in China actively smoke during pregnancy, but secondhand smoke exposure still exists. However, we did not find an association between ETFPT and the mother's exposure to secondhand smoke during pregnancy. Additionally, some previous studies have noted an association between breast feeding and the timing of the eruption of primary teeth, finding that children who were not breast fed had delayed tooth eruption ${ }^{49}$. The effect of breast feeding was also examined in this study, but we found that neither the breast feeding model nor the duration of breast feeding were significantly related to the ETFPT, which agreed with another report ${ }^{50}$.

Our study has a number of strengths. First, our participants were drawn from a systematic screening of pregnant women in a population-based, large study performed in Nanjing, China. Moreover, the relatively large sample size in this study provided good statistical power. There are also several limitations to this study. First, it used information from a cohort based on only one hospital in one city. The annual delivery rate of Nanjing babies in this hospital was about $20 \%$. Therefore, the results should be considered with caution. Second, some reported risk factors for ETFPT, such as sociodemographic and socioeconomic characteristics, were not considered for adjustment in this study due to the high percentage of missing data. Third, the data on the timing of tooth eruption were reported by the mothers and are thus subject to error. To further explore the link between primary tooth eruption and other postnatal factors, further studies are ongoing. In particular, future studies will explore the association between the eruption timing of primary teeth and the development of subsequent dental caries, which has received little attention in the literature. 


\begin{tabular}{|c|c|c|c|c|}
\hline \multirow[b]{2}{*}{ Factors } & \multicolumn{2}{|l|}{ Univariate analysis } & \multicolumn{2}{|l|}{ Multivariable analysis $^{\mathrm{b}}$} \\
\hline & $\beta(95 \% \mathrm{CI})$ & $P$ value & $\beta(95 \% \mathrm{CI})$ & $P$ value \\
\hline $\begin{array}{l}\text { Mother's childbearing age } \\
\text { (years) }\end{array}$ & $0.00(-0.03,0.04)$ & 0.845 & $0.00(-0.03,0.04)$ & 0.910 \\
\hline$<25$ & $0.12(-0.47,0.72)$ & 0.681 & $0.15(-0.44,0.74)$ & 0.620 \\
\hline $25-35^{\mathrm{a}}$ & - & - & - & - \\
\hline$>35$ & $0.53(0.10,0.95)$ & 0.015 & $0.57(0.13,1.02)$ & 0.010 \\
\hline \multicolumn{5}{|c|}{ Exposure to secondhand smoke } \\
\hline Yes & $0.22(-0.11,0.55)$ & 0.192 & $0.25(-0.07,0.58)$ & 0.130 \\
\hline $\mathrm{No}^{\mathrm{a}}$ & - & - & - & - \\
\hline \multicolumn{5}{|l|}{ Prepregnancy BMI $\left(\mathrm{kg} / \mathrm{m}^{2}\right)$} \\
\hline$<18.5$ & $0.04(-0.35,0.43)$ & 0.847 & $-0.02(-0.41,0.36)$ & 0.900 \\
\hline $18.5-23.9$ & - & - & - & - \\
\hline $24.0-27.9$ & $-0.06(-0.53,0.42)$ & 0.810 & $0.18(-0.30,0.66)$ & 0.460 \\
\hline$\geq 28.0^{\mathrm{a}}$ & $0.39(-0.53,0.42)$ & 0.483 & $0.32(-0.75,1.39)$ & 0.560 \\
\hline \multicolumn{5}{|l|}{ Parity } \\
\hline Multiparous & $-0.13(-0.44,0.17)$ & 0.381 & $-0.16(-0.49,0.17)$ & 0.340 \\
\hline \multicolumn{5}{|l|}{ Primiparous $^{a}$} \\
\hline \multicolumn{5}{|l|}{ Gestational age (weeks) } \\
\hline$<37$ & $0.59(0.05,1.13)$ & 0.032 & $0.01(-0.57,0.59)$ & 0.970 \\
\hline$\geq 37^{\mathrm{a}}$ & - & - & - & - \\
\hline \multicolumn{5}{|l|}{ Mode of delivery } \\
\hline Caesarean & $-0.01(-0.24,0.22)$ & 0.919 & $0.00(-0.23,0.24)$ & 0.980 \\
\hline Vaginal $^{a}$ & - & - & - & - \\
\hline \multicolumn{5}{|l|}{ Infant sex } \\
\hline Female & $0.30(0.07,0.52)$ & 0.009 & $0.26(0.07,0.52)$ & 0.022 \\
\hline Male $^{\mathrm{a}}$ & - & - & - & - \\
\hline \multicolumn{5}{|l|}{ Birth weight (g) } \\
\hline$<2500$ & $1.39(0.65-2.12)$ & $<0.001$ & $0.98(0.20,1.76)$ & 0.010 \\
\hline $2500-4000^{\mathrm{a}}$ & - & - & - & - \\
\hline$>4000$ & $-0.93(-1.43,-0.44)$ & $<0.001$ & $-0.79(-1.30,-0.28)$ & 0.000 \\
\hline \multicolumn{5}{|l|}{ Feeding model } \\
\hline Breast feeding & $0.18(-0.11,0.46)$ & 0.234 & $0.17(-0.12,0.46)$ & 0.250 \\
\hline Artificial feeding & $-0.12(-0.72,0.48)$ & 0.700 & $-0.18(-0.88,0.52)$ & 0.610 \\
\hline Mixed feeding ${ }^{a}$ & - & - & - & - \\
\hline \multicolumn{5}{|c|}{ Breast feeding duration (months) } \\
\hline$<6$ & $0.17(-0.24,0.58)$ & 0.423 & $0.08(-0.32,0.49)$ & 0.690 \\
\hline$\geq 6^{\mathrm{a}}$ & - & - & - & - \\
\hline
\end{tabular}

Table 2. Association of maternal, perinatal and postnatal information factors with ETFPT. ${ }^{\text {Reference group. }}$ Bold values indicate significant results. ${ }^{b}$ Adjusted for all factors except the investigated factor. *Abbreviations: ETFPT is eruption timing of the first primary tooth, CI is confidence interval, $\mathrm{kg}$ is kilograms, $\mathrm{m}$ is meters, $\mathrm{g}$ is grams.

\section{Conclusions}

Based on this study's findings, the following conclusions can be drawn:

1. Higher maternal childbearing age, female sex in infants and low infant birth weight were significantly associated with delayed ETFPT, while macrosomia was significantly associated with earlier ETFPT.

2. Considering the limitations of this study, no associations were observed between other maternal, perinatal or postnatal factors and ETFPT.

3. The ETFPT differs depending on infants' ethnicity and community, likely in response to variation in environmental, developmental and genetic factors.

\section{Methods}

Study design. This study was conducted according to the guidelines in the Declaration of Helsinki, and all procedures involving human subjects were approved by the Institutional Review Board of Nanjing Maternity and Child Health Care Institute. A total of 1296 singleton pregnant women in their first trimester were recruited between May 2014 and September 2015. The inclusion criteria included women who intended to give birth at the Affiliated Obstetrics and Gynecology Hospital of Nanjing Medical University and planned to reside in Nanjing, China, for the 5 years after being recruited into this study. The exclusion criteria included women who had 


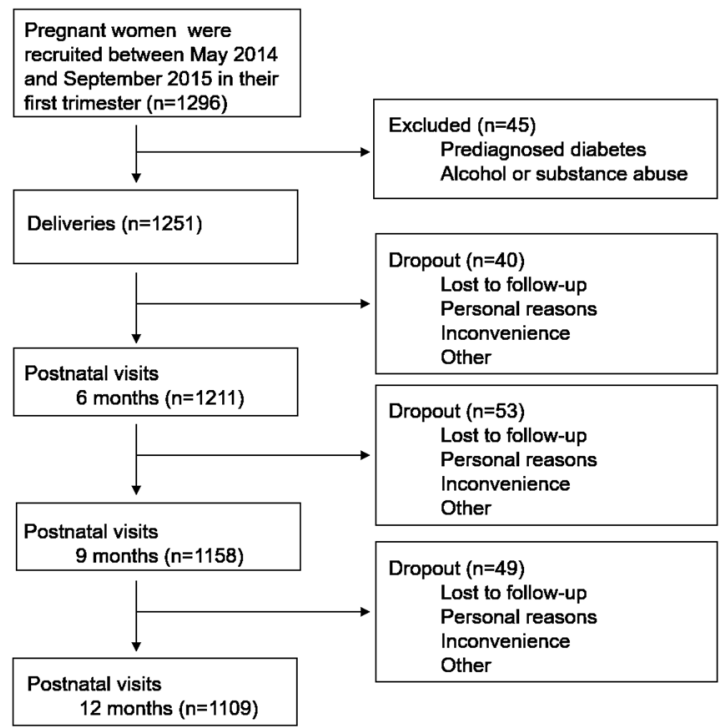

Figure 3. Recruited and follow-up process of the study.

\begin{tabular}{|l|l|}
\hline Potential factors & Description \\
\hline \multirow{5}{*}{ Maternal factors } & Maternal childbearing age (years): $(1)<25 ;(2) 25-35 ;(3)>35$ \\
\cline { 2 - 2 } & $\begin{array}{l}\text { Maternal prepregnancy BMI: (1) Underweight }\left(<18.5 \mathrm{~kg} / \mathrm{m}^{2}\right) ;(2) \mathrm{Normal}(18.5- \\
\left.23.9 \mathrm{~kg} / \mathrm{m}^{2}\right) ;(3) \text { Overweight }\left(24-27.9 \mathrm{~kg} / \mathrm{m}^{2}\right) ;(4) \text { Obese }\left(>28.0 \mathrm{~kg} / \mathrm{m}^{2}\right)\end{array}$ \\
\cline { 2 - 2 } & Exposure to secondhand smoke during pregnancy:(1) Yes; (2) No \\
\cline { 2 - 2 } & Parity:(1) Multiparous; (2) Primiparous \\
\cline { 2 - 2 } Perinatal factors & Gestational age (weeks): (1) $<37 ;(2) \geq 37$ \\
\cline { 2 - 2 } & Mode of delivery: (1) Caesarean; (2) Vaginal \\
\hline \multirow{3}{*}{ Postnatal factors } & Birth weight (g): (1) $<2500 ;(2) 2500-4000 ;(3)>4000$ \\
\cline { 2 - 2 } & Child's sex: (1) Male; (2) Female \\
\cline { 2 - 2 } & Feeding model: (1) Breast feeding; (2) Artificial feeding; (3) Mixed feeding \\
\cline { 2 - 2 } & Duration of breast feeding (months): (1) $<6 ;(2) \geq 6$ \\
\hline
\end{tabular}

Table 3. Factors tested for association with ETFPT*. *Abbreviations: ETFPT is eruption timing of the first primary tooth, $\mathrm{kg}$ is kilograms, $\mathrm{m}$ is meters, $\mathrm{g}$ is grams.

chronic diseases requiring medication (e.g., prediagnosed diabetes) and those who abused alcohol or substances. All participants signed written free informed consent forms for themselves and their children.

Maternal questionnaires and clinical data. Maternal general demographic information regarding childbearing age, prepregnancy BMI, pregnancy tobacco exposure, parity, personal health and family history of disease were collected from a detailed questionnaire. The clinical data of the women during pregnancy, including gestational age and delivery method, were extracted from hospital laboratory records.

The maternal childbearing age of the participants was divided into three groups: $<25$ years, $25-35$ years, $>35$ years. BMI was calculated as weight $(\mathrm{kg}) /$ height $(\mathrm{m})^{2}$. The World Health Organization $(\mathrm{WHO})$ criteria were used to classify the women's BMIs into four groups: underweight $\left(<18.5 \mathrm{~kg} / \mathrm{m}^{2}\right)$, normal $\left(18.5-23.9 \mathrm{~kg} / \mathrm{m}^{2}\right)$, overweight $\left(24-27.9 \mathrm{~kg} / \mathrm{m}^{2}\right)$, and obese $\left(>28.0 \mathrm{~kg} / \mathrm{m}^{2}\right)$. The infants' gestational age at birth was divided into two groups: low gestational age, which was less than 37 weeks, and normal gestational age, which was at least 37 weeks.

Perinatal details, such as infant sex and birth weight, were also obtained. Infant birth weight was divided into three groups: low birth weight $(<2500 \mathrm{~g})$, normal birth weight $(2500-4000 \mathrm{~g})$, and macrosomia $(>4000 \mathrm{~g})$.

Child questionnaires and oral examinations. Questionnaires regarding child factors, including feeding mode (breast feeding, artificial feeding or mixed feeding) and duration of breast feeding were collected at subsequent return visits. All oral examinations of the infants were performed at 6,9 , and 12 months of age by one experienced senior dentist. Meanwhile, a licensed dental assistant checked and recorded the data for each child. Training and calibration sessions were done before the oral examinations. Kappa was used to assess the intra-examiner reliability and the inter-examiner reliability. To this end, test-retest was done in first 20 samples for the observers and in 50 cases selected randomly, oral examinations were completed by the two examiners. The agreement between test and retest was $100 \%$ and the agreement between the dentist and the dental assistant was also excellent $(\mathrm{Kappa}=1)$. The examinations were performed under natural light in a dental chair. At each 
visit, the mothers were asked the age or date at which the child's first primary tooth erupted. The aim of the oral examinations was to ascertain the eruption of the child's first primary tooth and its eruption mode. The eruption of a tooth was defined as the appearance of any part of the tooth piercing the gum by using Federation Dentaire Internationale (FDI) standards ${ }^{51}$.

Of the total 1296 singleton pregnant women, 45 were excluded because of prediagnosed diabetes, alcohol or substance abuse, and 1251 live-born infants were delivered. During the 6-, 9-, and 12-month return visits, 40, 53 and 49 patients dropped out because of loss to follow-up, personal reasons, inconvenience and other factors. After 12 months of oral examinations, sufficient information was available for 1109 mother-child pairs to perform further analysis (Fig. 3).

Statistical analysis. Maternal, perinatal and postnatal information was collected to identify potential determinants of ETFPT (Table 3). Descriptive statistics, including means \pm standard deviations, minimums, maximums and frequencies (percentages) were calculated for all variables. For children with no tooth eruption at the age of one year, the maximum value was recorded as 13 months because the 12-month visit occurred when the child between 11 to 13 months old. Student's t-tests and Mann-Whitney U-tests were used to examine the difference in the ETFPT between groups. Chi-squared and Fisher exact tests were used to examine differences between percentage of children and ETFPT group. Univariate and multivariate linear regression models were used to identify the significant determinants linked to ETFPT. Statistical analyses were performed with R software (version 3.2.5), and $p<0.05$ was considered statistically significant.

\section{References}

1. Koussoulakou, D. S., Margaritis, L. H. \& Koussoulakos, S. L. A curriculum vitae of teeth: evolution, generation, regeneration. J. Int J Biol Sci. 5(3), 226-243 (2009).

2. Li, R. X. \& Hu, Y. A cross-sectional survey on the patterns of primary teeth eruption in 2581 children. J. Zhonghua Er Ke Za Zhi. 55(1), 37-41 (2017).

3. Burgueño Torres, L., Mourelle Martínez, M. R. \& de Nova García, J. M. A study on the chronology and sequence of eruption of primary teeth in Spanish children. J. Eur J Paediatr Dent. 16(4), 301-304 (2015).

4. Hughes, T. E. et al. Strong genetic control of emergence of human primary incisors. J. J Dent Res. 86(12), 1160-1165 (2007).

5. Pillas, D. et al. Genome-Wide Association Study Reveals Multiple Loci Associated with Primary Tooth Development during Infancy. PLoS Genet. 6(2), e1000856 (2010).

6. Psoter, W. J., Morse, D. E., Pendrys, D. G., Zhang, H. \& Mayne, S. T. Median ages of eruption of the primary teeth in white and Hispanic children from Arizona. J. Pediatr Dent. 25(3), 257-261 (2003).

7. Rantakallio, P. \& Mäkinen, H. The effect of maternal smoking on the timing of deciduous tooth eruption. J. Growth. 47(2), 122-128 (1983).

8. Żądzińska, E., Sitek, A. \& Rosset, I. Relationship between pre-natal factors, the perinatal environment, motor development in the first year of life and the timing of first deciduous tooth emergence. J. Ann Hum Biol. 43(1), 25-33 (2016).

9. Aktoren, O., Tuna, E. B., Guven, Y. \& Gokcay, G. A study on neonatal factors and eruption time of primary teeth. J. Community Dent Health. 27(1), 52-56 (2010).

10. Sajjadian, N., Shajari, H., Jahadi, R., Barakat, M. G. \& Sajjadian, A. Relationship between birth weight and time of first deciduous tooth eruption in 143 consecutively born infants. J. Pediatr Neonatol. 51(4), 235-237 (2010).

11. Bastos, J. L., Peres, M. A., Peres, K. G. \& Barros, A. J. Infant growth, development and tooth emergence patterns: A longitudinal study from birth to 6 years of age. J. Arch Oral Biol. 52(6), 598-606 (2007).

12. Delgado, H. et al. Nutritional status and the timing of deciduous tooth eruption. J. Am J Clin Nutr. 28(3), 216-224 (1975).

13. Pavičin, I. S., Dumančić, J., Badel, T. \& Vodanović, M. Timing of emergence of the first primary tooth in preterm and full-term infants. J. Ann Anat. 203, 19-23 (2016).

14. Alnemer, K. A., Pani, S. C., Althubaiti, A. M. \& Bawazeer, M. Impact of birth characteristics, breast feeding and vital statistics on the eruption of primary teeth among healthy infants in Saudi Arabia: an observational study. BMJ Open. 7(12), e018621 (2017).

15. Oziegbe, E. O., Adekoya-Sofowora, C., Folayan, M. O., Esan, T. A. \& Owotade, F. J. Relationship between socio-demographic and anthropometric variables and number of erupted primary teeth in suburban Nigerian children. J. Matern Child Nutr. 5(1), 86-92 (2009).

16. Viscardi, R. M., Romberg, E. \& Abrams, R. G. Delayed primary tooth eruption in premature infants: relationship to neonatal factors. J. Pediatr Dent. 16(1), 23-28 (1994).

17. Mg'ang'a, P. M. \& Chindia, M. L. Dental and skeletal changes in juvenile hypothyroidism following treatment: case report. J. Odontostomatol Trop. 13(1), 25-27 (1990).

18. Must, A., Phillips, S. M., Tybor, D. J., Lividini, K. \& Hayes, C. The association between childhood obesity and tooth eruption. J. Obesity (Silver Spring). 20(10), 2070-2074 (2012).

19. Lal, S. et al. Accelerated tooth eruption in children with diabetes mellitus. J. Pediatrics. 121(5), e1139-1143 (2008).

20. Martín Moreno, V., Molina Cabrerizo, M. R. \& Gómez Gómez, C. Relationship among the eruption of the first temporal teeths, the breast feeding duration and the anthropometric development in the first two years of life. J. Nutr Hosp. 21(3), 362-368 (2006).

21. Seow, W. K. A study of the development of the permanent dentition in very low birthweight children. J. Pediatr Dent. 18(5), 379-384 (1996).

22. Caixeta, F. F. \& Corrêa, M. S. Evaluation of the dental eruption pattern and of enamel defects in the premature child. J. Rev Assoc Med Bras. 51(4), 195-199 (2005).

23. Sahin, F. et al. Factors affecting the timing of teething in healthy Turkish infants: a prospective cohort study. J. Int J Paediatr Dent. 18(4), 262-266 (2008).

24. Un Lam, C. et al. Influence of metabolic-linked early life factors on the eruption timing of the first primary tooth. J. Clin Oral Investig. 20(8), 1871-1879 (2016).

25. Ntani, G. et al. Maternal and early life factors of tooth emergence patterns and number of teeth at 1 and 2 years of age. J. J Dev Orig Health Dis. 6(4), 299-307 (2015).

26. Townsend, N. \& Hammel, E. A. Age estimation from the number of teeth erupted in young children: an aid to demographic surveys. J. Demography. 27(1), 165-174 (1990).

27. Holman, D. J. \& Jones, R. E. Longitudinal analysis of deciduous tooth emergence: III. Sexual dimorphism in Bangladeshi, Guatemalan, Japanese, and Javanese children. J. Am J Phys Anthropol. 122(3), 269-278 (2003).

28. Reed, B. A., Habicht, J. P. \& Niameogo, C. The effects of maternal education on child nutritional status depend on socioenvironmental conditions. J. Int J Epidemiol. 25(3), 585-592 (1996).

29. Warren, J. J. et al. Timing of primary tooth emergence among U.S. racial and ethnic groups. J. J Public Health Dent. 76(4), 259-262 (2016). 
30. Kariya, P., Tandon, S., Singh, S. \& Tewari, N. Polymorphism in emergence of deciduous dentition: A cross-sectional study of Indian children. J. J Investig Clin Dent. 9(1) (2018).

31. Verma, N. et al. Eruption Chronology in Children: A Cross-sectional Study. J. Int J Clin Pediatr Dent. 10(3), 278-282 (2017).

32. Billings, R. J., Berkowitz, R. J. \& Watson, G. Teeth. J. Pediatrics. 113(4), 1120-1127 (2004).

33. Woodroffe, S. et al. Primary tooth emergence in Australian children: timing, sequence and patterns of asymmetry. J. Aust Dent J. 55(3), 245-251 (2010).

34. Soliman, N. L., El-Zainy, M. A., Hassan, R. M. \& Aly, R. M. Timing of deciduous teeth emergence in Egyptian children. J. East Mediterr Health J. 17(11), 875-881 (2011).

35. Savage, T. et al. Increasing maternal age is associated with taller stature and reduced abdominal fat in their children. PLoS One 8(3), e58869 (2013).

36. Maki, K., Morimoto, A., Nishioka, T., Kimura, M. \& Braham, R. L. The impact of race on tooth formation. J. ASDC J Dent Child. 66(5), 353-356, 294-295 (1999).

37. Choi, N. K. \& Yang, K. H. A study on the eruption timing of primary teeth in Korean children. J. ASDC J Dent Child. 68(4), 244-249, 228 (2001).

38. Hägg, U. \& Taranger, J. Timing of tooth emergence. A prospective longitudinal study of Swedish urban children from birth to 18 years. J. Swed Dent J. 10(5), 195-206 (1986).

39. Ramirez, O., Planells, P. \& Batberia, E. Age and Order of Eruption of Primary Teeth in Spanish Children. J. Community Dent Oral Epidemiol. 22(1), 56-59 (1994).

40. Zadzińska, E., Nieczuja-Dwojacka, J. \& Borowska-Sturgińska, B. Primary tooth emergence in Polish children: timing, sequence and the relation between morphological and dental maturity in males and females. J. Anthropol Anz. 70(1), 1-13 (2013).

41. Tanguay, R., Demirjian, A. \& Thibault, H. W. Sexual dimorphism in the emergence of the deciduous teeth. J. J Dent Res. 63(1), 65-68 (1984).

42. Infante, P. F. \& Owen, G. M. Relation of chronology of deciduous tooth emergence to height, weight and head circumference in children. J. Archs Oral Biol. 18(11), 1411-1417 (1973).

43. Gaur, R. \& Kumar, P. Effect of undernutrition on deciduous tooth emergence among Rajput children of Shimla District of Himachal Pradesh, India. J. Am J Phys Anthropol. 148(1), 54-61 (2012).

44. Harris, E. F., Barcroft, B. D., Haydar, S. \& Haydar, B. Delayed tooth formation in low birth-weight African-American children. J. Pediatr Dent. 15(1), 30-35 (1993).

45. Ramos, S. R., Gugisch, R. C. \& Fraiz, F. C. The influence of gestational age and birth weight of the newborn on tooth eruption. J. J Appl Oral Sci. 14(4), 228-232 (2006).

46. Neto, P. G. \& Falcão, M. C. Eruption chronology of the first deciduous teeth in children born prematurely with birth weight less than 1500 g. J. Rev Paul Pediatr. 32(1), 17-23 (2014).

47. World Health Organization. WHO Report on the Global Tobacco Epidemic, 2017, Country Profile China. 2017, http://www.who. int/tobacco/surveillance/policy/country_profile/chn.pdf?ua=1 (2017)

48. Xianglong, X. et al. Smoking in pregnancy: a cross-sectional study in China. J. Tob Induc Dis. 15, 35 (2017)

49. Holman, D. J. \& Yamaguchi, K. Longitudinal analysis of deciduous tooth emergence: IV. Covatiate effects in Japanese children. J. Am J Phys Anthropol. 126(3), 352-358 (2005).

50. Folayan, M. O., Oziegbe, E. O. \& Esan, A. O. Breastfeeding, timing and number of erupted teeth in first twelve months of life in Nigerian children. J. Eur Arch Paediatr Dent. 11(6), 279-282 (2010).

51. Anita, G. et al. Emergence of Primary Teeth in Children of Sunsari District of Eastern Nepal. J. McGill Journal of Medicine. 10(1), 11-15 (2007).

\section{Acknowledgements}

This study was financially supported by the Science and Technology Development Fund of Nanjing Medical University (2016NJMUZD064, 2016NJMUZD065).

\section{Author Contributions}

Huaying Wu, Ting Chen, Yaming Chen and Kaipeng Xie were involved in the study design. Huaying Wu, Xiangqin Xu and Qian Ma were involved the data collection. Huaying Wu, Ting Chen and Kaipeng Xie performed the data analyses and drafted the manuscript. All the authors reviewed and revised the manuscript and approved the final manuscript as submitted.

\section{Additional Information}

Competing Interests: The authors declare no competing interests.

Publisher's note: Springer Nature remains neutral with regard to jurisdictional claims in published maps and institutional affiliations.

(c) (i) Open Access This article is licensed under a Creative Commons Attribution 4.0 International (c) License, which permits use, sharing, adaptation, distribution and reproduction in any medium or format, as long as you give appropriate credit to the original author(s) and the source, provide a link to the Creative Commons license, and indicate if changes were made. The images or other third party material in this article are included in the article's Creative Commons license, unless indicated otherwise in a credit line to the material. If material is not included in the article's Creative Commons license and your intended use is not permitted by statutory regulation or exceeds the permitted use, you will need to obtain permission directly from the copyright holder. To view a copy of this license, visit http://creativecommons.org/licenses/by/4.0/.

(c) The Author(s) 2019 